\title{
The Effects of Lecture Diversity on Germane Load
}

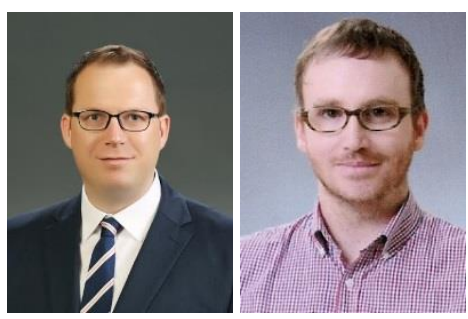

Jamie Costley and Christopher Lange

Kongju National University, College of Education, Gongju, South Korea, Joongbu University, Department of Liberal Arts, Geumsan, South Korea

\begin{abstract}
An important aspect of MOOCs is the way students interact with video lectures. Instruction provided through video lectures should focus on ways to increase germane cognitive load, which directly contributes to learning. One approach that may lead to an increase of germane load may be to use video lectures with diverse forms of media, including both auditory and visual aspects of multimedia. This study surveyed a group of students $(\mathrm{n}=1602)$ who participated in MOOC-like courses in South Korea to investigate the relationship between delivery diversity and germane cognitive load. Additionally, the relationships between individual indicators of both audio and visual aspects of multimedia and germane load were examined. Results show a positive relationship between diverse media delivery (auditory, visual, and total media) and germane cognitive load. The implication of these results are important for instructors who wish to promote a better understanding of e-learning materials through the delivery of content by using diverse forms of media.
\end{abstract}

Keywords: e-learning, cognitive load, germane load, lecture delivery, MOOCs, multimedia, video lectures

\section{Introduction}

MOOCs provide open access, online courses with the potential for unlimited participation (Kaplan \& Haenlein, 2016). They offer an alternative to brick and mortar institutions, with the goal of providing an effective learning experience within an online environment (Lee \& Lee, 2015). Perceived benefits to students of online learning include flexibility of course schedule, availability of a wide range of courses, and access to courses students may not have otherwise taken (National Center for Education Statistics [NCES], 2008). MOOCs are reflective of the online learning experience as a whole, as they are designed to be flexible and time efficient, while offering courses at little to no cost (Yuan \& Powell, 2013). Recent developments have led to the establishment of MOOCs associated with partner universities, which offer online courses for credit (Yuan \& Powell, 2013). The method of delivery within MOOCs generally consists of video lectures along with various associated content, while 
feedback is presented through user interaction or system automation within the video lectures themselves (Alraimi, Zo, \& Ciganek, 2015).

The use of video lectures is a central feature of the e-learning experience (Breslow, Pritchard, DeBoer, Stump, Ho, \& Seaton, 2013). The relationship between effective implementation of video lectures and other aspects of online environments needs to be understood to maximize the impact of e-learning lessons. One of the ways in which e-learning instructors have sought to improve the learning experience is through diverse lectures that integrate various forms of media (Kim, Kwon, \& Cho 2011; Owston, Lupshenyuk, \& Wideman, 2011; Zhang, D., Zhao, Zhou, \& Nunamaker, 2004). It is worth investigating whether such diversity engages students in a way that may improve their understanding of the material. This can be examined by looking at how lecture diversity affects germane load, which has been widely accepted as contributing to learning through a greater understanding of material being delivered by instructors (Cierniak, Scheiter, \& Gerjets, 2009; De Jong, 2010; Kolfschoten, Lukosch, Verbraeck, Valentin, \& Vreede, 2010; Sweller, 2005; Sweller, Van Merriënboer, \& Paas, 1998).

Cognitive load theory examines ways in which learners use their working memory for transferring information into their long-term memory (Cierniak et al., 2009). According to cognitive load theory, there is a limited capacity of stored information within the working memory. For this reason, instruction should focus on limiting unnecessary information processing within the working memory, and promote the processing of information that is relevant to the learning process (Cierniak et al., 2009). Cognitive load theory identifies three main elements that make up cognitive processing: intrinsic load, extraneous load, and germane load (De Jong, 2010; Sweller, 2005; Sweller, Van Merriënboer, \& Paas, 1998). The level of content complexity combined with students' prior knowledge represents intrinsic load (Cierniak et al., 2009; Shadiev, Hwang, Huang, \& Liu, 2015; Sweller \& Chandler, 1994; Cierniak, et al., 2009; Shadiev et al., 2015). Poor instruction often leads to extraneous load, which creates unnecessary processing in the working memory, leading to lower levels of germane load (Cierniak et al., 2009; Leppink, Paas,Van der Vleuten, Van Gog, \& Van Merriënboer, 2013; Schmeck, Opfermann, van Gog, Paas, \& Leutner, 2015). Germane load is the only aspect of cognitive load theory where higher levels are considered more useful to the learning process (Cierniak et al., 2009). Germane load directly contributes to learning, and is a reflection of student effort to construct schema used for better comprehension of information involved in cognitive processing (Kolfschoten, Lukosch, Verbraeck, Valentin, \& Vreede, 2010; Sweller et al., 1998).

Diverse media delivery plays a role in how the students perceive lectures, and ultimately can affect the students' cognitive processing (Kalyuga, Chandler, \& Sweller, 1999; Mayer \& Moreno, 2003; Lowe, 1999; Mayer, 2014; Sims \& Hegarty, 1997; Rasch \& Schnotz, 2009; Schnotz \& Rasch, 2005; Sweller, 1999; Sweller et al., 1998; Van Merriënboer, 1997). However, there are conflicting ideas in this area, with some research advocating the use of diverse forms of media to promote germane load, and other research claiming that media diversity can actually be detrimental for the development of germane load. For example, some research claims that providing the same content multiple times through various forms of media helps students to gain a better understanding of the content (Baggett, 1984; Paivio, 1991; Schmidt-Weigand \& Scheiter, 2011; Verdi \& Kulhavy, 2002), while other research claims that this causes a redundancy effect, which leads to unnecessary cognitive processing (Kalyuga, Chandler, \& Sweller, 1999; Mayer \& Moreno, 2003). This redundancy effect can decrease germane 
load (Sweller et al., 1998). The use of animation rather than still images is a point of contention among researchers. Some support its facilitating effect to promote a better understanding of the content over still images (Lowe, 1999; Sims \& Hegarty, 1997), while others claim that deeper cognitive processing associated with still images is actually more beneficial to gaining a better understanding of the content (Schnotz \& Rasch, 2005). Additionally, videos of professors speaking accompanied by text has been promoted for better understanding of the content by some researchers (Day, Foley, \& Catrambone, 2006; Kizilcec, Bailenson, \& Gomez, 2015), and discouraged by others as possibly causing students to use unnecessary cognitive processing by splitting their attention between the video and the text (Kalyuga et al., 1999; Sweller, 1999; Mayer \& Moreno, 2003). Finally, discrepancies within research involving the use of auditory media exist as well, with some claiming that music and sound added to the lecture contributes to more learning (Sun \& Cheng, 2007), and others claiming that it serves as a cognitive distraction, negatively affecting the comprehension of the content being delivered at that specific time (Mayer \& Moreno, 2003). Much of the research claiming that various forms of multimedia negatively affects germane load, does so by looking at isolated situations occurring in specific moments within the lecture. This paper looks at the bigger picture of what is going on over the course of a lecture and seeks to see how a combination of multimedia has an effect on germane load.

\section{Theoretical Background}

\section{Total Diversity and Learning Theories}

E-learning lectures typically contain various forms of media, with both auditory and visual components representing the content delivered to the students. Mayer (2014) describes the differing categories of both auditory and visual media. Auditory media is represented by spoken text, speech, and narration, while visual media includes illustrations, images, graphs, maps, animations, and words in the form of slides and rolling text. From a cognitive perspective, students organize this information in their working memory and use it to construct schema, which ultimately plays a role in understanding the material (Mayer, 2014; Sweller, 1999). Theories have been used to explain how both auditory and visual media should contribute to a better understanding of the content. The dual coding theory states that cognitive processing effectively takes place through the use of verbal (text and speech) and nonverbal (graphics and animation) cognitive channels, which are often interconnected with each other (Paivio, 1991). For example, when a verbal explanation of content is accompanied by an image supporting that explanation, two separate representations are internally integrated to make sense of the content (Schmidt-Weigand \& Scheiter, 2011). The Generative Theory of multimedia learning (Mayer, 1997; 2014) states that if both auditory and visual media are combined, students will learn more than through auditory media alone because students are able to make cognitive connections between the two formats. For example, presenting content through verbal explanation of pictures allows students to make internal connections between both representations (auditory and visual), making the content more accessible and easier to recall than if the content was delivered through verbal description alone (Schmidt-Weigand \& Scheiter, 2011). The active processing theory adds to the generative theory by describing the specific cognitive process of selecting, organizing, and integrating visual and auditory media to make connections between the two channels, 
further increasing students' understanding of the content (Mayer \& Moreno, 2003). Additionally the modality principle states that using auditory media, narration for example, to replace on-screen text, not only helps make connections between the speech and an image, it also frees up additional cognitive space in the visual channel, allowing for better cognitive processing (Moreno \& Mayer, 1999). Furthermore, both auditory and visual media are more effective in making connections between the content when they are used simultaneously, as stated by the continuity principle (Mayer \& Anderson, 1991; Moreno \& Mayer, 1999).

\section{Empirical Research Supporting Total Diversity}

Empirical research has added support to theoretical claims that using both auditory and visual media promotes germane load by providing a better understanding of the content being delivered. As early as 1991, Clark and Paivio found that higher levels of learning were more evident through the use of dual-channel integration of both verbal and nonverbal media than through the use of either verbal or nonverbal media alone. Mayer and Anderson (1992) showed that when material was presented through the delivery of animation and narration concurrently rather than successively, students retained more of the information than through dual coding of audio and visual media. Day et al. (2006) examined the effects of various media delivery styles over the course of a lesson. Post-test retention scores and perceived levels of comprehension indicated that the more diverse in terms of audio and visual the lessons were, the more students retained and understood information (Day et al., 2006). Kim et al. (2011) examined students' perceived levels of learning when diverse audio and visuals were combined throughout lectures, with their results showing that students who received media integration such as images, graphics, audio, and video clips showed higher levels of perceived learning. Zhang, Zhou, Briggs, and Nunamaker (2006) also found empirical evidence that a variety of total media diversity is beneficial to the learning process. Results showed that lectures that contained both auditory and visual delivery (PPT slides and video with audio) led to higher learning outcomes than those that only contained visual delivery (PPT slides and lecture notes). These studies provide support for the notion that total media delivery is useful for increasing student germane load by increasing student learning and understanding of the content within e-learning lectures.

\section{Potential Drawbacks to Total Diversity}

Although research shows that in a general sense, total diversity has a positive effect of how students understand the content within a lecture, there are specific circumstances where combining differing types of multimedia can negatively affecting germane load. Mayer and Moreno (2003) discuss the fact that learners who have to split their attention from separated sources increase cognitive processing, which may reduce germane load. This effect can come into play when both audio and visual media is presented to the students. Kizilcec et al. (2015), for example, discuss the problem of not fully comprehending the content when students split their attention between auditory and visual media, such as a video with the instructor's voice and text complimenting each other. In this situation, learners may not fully comprehend the lectures because they cannot focus on important aspects of the lecture or may be distracted by the variety of media. To combat such cognitive overload, Moreno and Mayer (2003) recommend incorporating written text into the existing spoken text through a process known as offloading in order to minimize the sources creating split attention. The redundancy effect represents another potential problem when using both auditory and visual media within a specific circumstance (Sweller et al., 1998). In this case, presenting the same information in varied ways, for 
example, text on a slide, the professor explaining something, and a pictorial representation of the same thing, essentially gives the learners the same information in three different ways. This is redundant, and can increase the amount of cognitive processing a learner is required to do in order to follow the lecture. Although multiple representations of content through various forms of media may sometimes be beneficial, Mayer and Moreno (2003) suggest the elimination of any redundant information that may overload cognitive processing. Mayer and Moreno (2003) also discusses the need to segment presentations involving narration of images or animation that occur at a high rate of speed. In these situations, students are potentially cognitively overloaded with information, without having the necessary time to process both auditory and visual information. Segmenting the presentation allows for students to control the pace by watching a segment of the video, thinking about the information, and then continuing on to the next segment when they are ready. It is therefore apparent that when using total media diversity, caution should be applied to ensure it is used properly.

\section{Auditory Media and Theories}

According to the cognitive theory of multimedia (Mayer, 2014) cognitive processing of audio media involves storing schema in the auditory working memory, which ultimately has an effect on learning and understanding the content. Multimedia that requires use of the auditory channel includes music, sound effects, spoken text, instructor's voice, and narration (Kizilcec et al., 2015; Mayer \& Moreno, 2003; Moreno \& Mayer, 1999). It has been theorized that using narration to deliver the content rather than text, creates an advantage when cognitively transferring information from working memory to long-term memory (Mayer \& Moreno, 2003; Moreno \& Mayer, 1999). Within an e-learning lecture, the use of the professor's voice to deliver instruction is supported by the personalization principle, which suggests explanation of content through a human voice that emphasizes social cues and has a less formal speaking style is beneficial for learning (Austin, 2009). This is based on the human need to socially interact with other humans, and doing so within computer mediated learning should be helpful in evoking learned social responses that are useful for learning (Kizilcec et al., 2015). When auditory words of the professor speaking are given added emphasis, it should also be more effective for retaining information through a process known as signaling (Mautone \& Mayer, 2001; Mayer \& Moreno, 2003). This can be done by stressing key words of speech within spoken content in a way that allows students to make better use of their cognitive processing by selecting and organizing relevant information. Speech is not the only use of audio that can promote understanding of the content within an e-learning lecture. Music and sound effects play a role as well, and the benefits of these two types of media is supported by the arousal theory, which states that adding the element of entertaining audio such as sound effects and music helps to increase attention and further promotes cognitive processing and further enhances retention (Weiner, 1990; Renninger, Hidi, \& Krapp, 1992).

\section{Empirical Research Supporting Use of Auditory Multimedia}

Evidence from experimental conditions using auditory delivery of multimedia has been presented to support theory. Research has shown that students who received content delivery through narration had a better learning experience than those that received the content through on-screen text, with results showing that the students in narration conditions being able to retain and transfer information more successfully (Moreno \& Mayer, 1999; Mousavi, Low, \& Sweller, 1995). Supporting evidence of the personalization principle was found by Atkinson, Mayer, and Merrill (2005), which showed that using a human voice to deliver content had a more positive effect on learning than using a computer- 
generated voice, as was evidenced by the students' increased ability to understand how to solve specific problems when instructed by the human voice. Additionally, stressing parts of speech to emphasize specific aspects of the content was shown to increase understanding of the multimedia lesson through more effective use of problem-solving transfer than when this type of signaling was not used (Mautone \& Mayer, 2001). Mautone and Mayer (2001) postulated that the signaling used in the instructor's speech may have contributed to a decrease in extraneous cognitive processing, therefore allowing them to better use what they learned to solve new problems. Finally, evidence points to the use of non-speech auditory media contributing to the learning process, as both sound effects and music have been shown to have a positive effect on learning and attention (Alwitt, Anderson, Lorch, \& Levin, 1980; Calvert \& Gersh, 1987; Calvert \& Scott, 1989; Mann, 1979; Wagley, 1978).

\section{Potential Drawbacks to the Use of Auditory Multimedia}

The use of auditory multimedia within e-learning has not always been viewed in positive light, as it can be detrimental to the learning experience when it creates cognitive overload. Because of this, some research advocates less varied audio in order to free up cognitive processing so that learning content can be better understood. For example, Mayer and Moreno (2003) claim that adding extraneous sound effects and background music to a lesson requires learners to partake in unnecessary cognitive processing that does not contributing to learning, which results in a decrease in germane load. Additionally, the limited capacity theory has been used to warn against the use of unnecessary audio within an e-learning lecture, claiming that the auditory channel of cognitive processing allows for a limited amount of information, and that extraneous audio should be avoided when delivering content within e-learning lectures due to its negative effect on transfer and retention (Chandler \& Sweller, 1991; Mayer \& Moreno, 2003; Sweller, 1999). Empirical support of this notion is evident in a study conducted by Moreno and Mayer (2000) that showed that adding interesting, yet irrelevant background music to the lecture had a negative effect on knowledge acquisition. Although such audio may at times help to capture students' attention, it has also been shown to negatively affect cognitive processing as well.

\section{Visual Media Theories}

Visual multimedia is represented by a variety of forms including, illustrations, graphs, photos, maps, animations, and video (Kizilcec et al., 2015; Mayer, 2014; Mayer \& Moreno, 2003; Schmidt-Weigand \& Scheiter, 2011; Schnotz \& Rasch, 2005). Some theories advocate the use of visual media within elearning environments to promote a better learning experience. It has been suggested, for example, that visual media helps students reason and make inferences, further reducing cognitive load (Goldstone \& Son, 2005; Zhang, 1997). Furthermore, claims have been made that visual media facilitate recall of information because of how it is represented in the memory, further allowing it to enhance procedural knowledge by integrating new information to prior knowledge (Mayer \& Moreno, 2003; Paivio, 1991; Schnotz \& Rasch, 2005). Specifically, images have been said to have a facilitating function when it comes to understanding processes, because learners can visually see how the process occurs rather than imagining it through explanation (Lowe, 1999; Sims \& Hegarty, 1997; Schnotz \& Rasch, 2005; Rasch \& Schnotz, 2009; Salomon, 1994; Sweller \& Chandler, 1994; van Gog, Ericsson, Rikers, \& Paas, 2005). The use of animation creates a greater facilitating function in that unlike static images, it often portrays a specific process with more detail, further freeing cognitive space of the learner (Lowe, 1999; Sims \& Hegarty, 1997). Additionally, written animated text that is added to a 
lecture may help avoid the transient information effect, which occurs when information that may be needed to make connections later in the lecture is lost shortly after it is delivered by the instructor (Luzón \& Letón, 2015; Wong, Leahy, Marcus, \& Sweller, 2012). It is thought that the addition of animated text to a lecture can help to leave a cognitive impression in the mind of the learner, helping them to recall the information at a later time (Luzón \& Letón, 2015). Video represents a visual media that helps the students in the learning process. Video of the instructor delivering content can be beneficial to the learning experience through non-verbal social cues that help to increase comprehension (Kizilcec et al., 2015).

\section{Empirical Research Supporting the Use of Visual Media}

Supporting research shows evidence that using visual multimedia is helpful to the learning process. For example, the facilitating function that animations and images have on the learner has been found to not only be valid, but beneficial for learning as well (Schnotz \& Rasch, 2005). Furthermore, studies have shown that the use of animation was effective in enabling cognitive processes that could not have been performed without the animation or simulated images (Salomon, 1994; Sweller \& Chandler, 1994; van Gog et al., 2005). The use of animated text was also shown to have a positive effect on the learning process. Luzón \& Letón (2015) showed that adding hand-written animated text to an elearning lesson is more effective in facilitating the learning of the content compared to when animated text was not used. Animated text specifically enhanced the learning experience by allowing the students to effectively select information, build representation models, and make sense of the material being delivered to them by the instructor (Luzón \& Letón, 2015). Finally, lecture delivery through the use of video of the professor has also been shown to help the students with learning. Day et al. (2006) for example, found that when video of the professor was added to an e-learning lecture, higher retention, and transfer rates were produced by the students than when no video of the professor was used.

\section{Potential Drawbacks to the Use of Visual Media}

Some research claims that caution is needed when using visual media such as simulated pictures or animation, particularly when used under specific conditions. Although it is widely accepted that the use of visual media does indeed provide a facilitating effect (Lowe, 1999; Sims \& Hegarty, 1997; Schnotz \& Rasch, 2005; Rasch \& Schnotz, 2009; Salomon, 1994; Sweller \& Chandler, 1994; van Gog, Ericsson, Rikers, \& Paas, 2005), some research claims that the facilitating effect is not always beneficial for learning for specific types of learners (Schnotz \& Rasch, 2005; Rasch \& Schnotz, 2009). For example, the claim has been made that it often leads to unnecessary cognitive processing for learners who have the ability to understand the information without the use of the images or animation (Rasch \& Schnotz, 2009; Schnotz \& Rasch, 2005). Schnotz and Rasch (2005) state that using this type of media can actually decrease germane load for students who don't need it to understand the content due to unnecessary cognitive processing. Some research also warns against improper use of videos containing the professor delivering the lecture. Although Kizilcec et al. (2015) claim that there are benefits to using video of the professor during a lecture, they claim that continuous use of video of the professor talking may actually cause cognitive overload by forcing students to overuse their working memory while watching the professor, especially when the professor directs their attention to specific content of the lesson. In order to overcome this problem, video of the professor needs to be used sporadically at times where focus of relevant content is not needed 
elsewhere (Kizilcec et al., 2015).

\section{The Current Study}

Existing research has examined the relationship between multimedia delivery and its effectiveness on learning, specifically on its ability to impact comprehension and increase germane load levels of elearners (Kalyuga, Chandler, \& Sweller, 1998; Mayer \& Moreno, 2003; Lowe, 1999; Mayer, 2014; Sims \& Hegarty, 1997; Rasch \& Schnotz, 2009; Schnotz \& Rasch, 2005; Sweller, 1999; Sweller et al., 1998; Van Merriënboer, 1997). Various studies have added empirical support to theoretical claims about the positive effects of delivery of auditory media, visual media, or a combination of both, (Alwitt et al., 1980; Atkinson, et al., 2005; Calvert \& Gersh, 1987; Calvert \& Scott, 1989; Day et al., 2006; Kim et al., 2011; Luzón \& Letón, 2015; Mann, 1979; Moreno \& Mayer, 1999; Mautone \& Mayer, 2001; Salomon, 1994; Sweller \& Chandler, 1994; Wagley, 1978; van Gog et al., 2005; Zhang et al., 2006). Research is inconsistent in regards to the effect of multimedia delivery on germane load, with some studies claiming that it can actually have a negative effect on processing the learning materials, and ultimately germane load (Chandler \& Sweller, 1991; Kizilcec et al., 2015; Mayer, 2014; Mayer \& Moreno, 2003; Rasch \& Schnotz, 2009; Schnotz \& Rasch, 2005; Sweller, 1999; Sweller et al., 1998). However those studies generally look at the effect of multimedia on germane load under specific conditions that occur during a particular part of the lecture. This paper seeks to examine the big picture by looking at how multimedia delivery, including specific aspects of multimedia delivery, affect germane load. Furthermore, this paper looks at three types of multimedia including total diversity, auditory diversity, and visual diversity. The findings of this study should be of practical use to e-learning instructors who wish to promote a better understanding of the material through the delivery of specific types of media.

\section{Research Hypotheses}

H1. Lecture diversity has a positive relationship with germane load.

H2. Audio diversity has a positive relationship with germane load.

H3. Visual diversity has a positive relationship with germane load.

\section{Methods}

\section{Context and Participants}

Effective use of video lectures is specifically an important aspect of MOOC-like courses within a Korean setting. MOOCs in general have been shown to have participation issues, as students involved with them often fail to successfully stay motivated and engage in the content (Yuan \& Powell, 2013). Keeping students interested in the content is particularly imperative in South Korea, where online lectures are generally reflective of traditional teacher-centered offline lectures (Lim, Kang, \& Park, 2016). This is reflective of deep-rooted cultural norms based on hierarchical respect, where students are expected to be mere recipients of content delivered to them by their instructors (Lim et al., 2016). Breaking traditional Korean cultural norms may be a difficult and sensitive issue, but designing video lectures to capture the interest of Korean students as the target group may help to overcome the 
downside associated with the possible lack of engagement in Korean e-learning environments. For example, Korean e-learning students have been found to prefer highly detailed, graphic-oriented content to be delivered to them within online learning contexts (Leppisaari, Herrington, Vainio, \& Im, 2013).

Participants of this study responded to survey questions about a specific MOOC-like course they had taken in the Open Cyber University (OCU) in South Korea. The OCU was founded in 1997 with educational services being provided to students by late 1998 (Jung \& Rha, 2001). Funded by a network of traditional universities for use by their students, the OCU offers degree programs for students enrolled in the OCU membership universities, commonly referred to as the consortium. Additionally, non-degree courses are offered for adults not enrolled in the membership universities (Moore \& Kearsley, 2011). Although students not affiliated with the member universities are required to pay tuition on a per-credit basis, students of the consortium are not required to pay any additional tuition for taking courses in the OCU. Currently, the OCU is the largest cyber university consortium in Korea, with 35 member universities providing about 400 courses for approximately 120,000 students every year (Han, 2012).

The content and design of the online courses are provided by the membership universities of the OCU (Jung \& Rha, 2001). Online courses within the OCU are generally delivered with web-based instruction consisting of little to no human interaction for the students who are also enrolled in the member university, while non-degree courses for adults may consist of a certain amount of face-toface meetings in addition to the online component of the course (Jung \& Rha, 2001). The justification for this OCU policy is that students not associated with the offline member universities lack the traditional face-to-face interaction that the other students do as part of their traditional university classes.

To help manage the OCU, a council consisting of representatives from the member universities was created to help with policy-making and management decisions (Jung \& Rha, 2001). Additionally, a management team of programmers and instructional designers was also put together to construct the virtual learning programs used in the OCU. To monitor the success of the OCU and attend to the needs of the students, an evaluation team was put together. Course evaluations are affected by the number of enrolled students, course completion rates, and student comments. According to the OCU homepage, the OCU was selected as the best cyber university in Korea based on 21 evaluation indicators, including student's willingness to learn, student loyalty, faculty professionalism, and appropriateness of professional personnel (About OCU, n.d.).

The survey that was part of this study was filled out by students attending classes in the OCU in the first semester of 2016. There were 1801 students who submitted surveys. Out of the 1801 surveys that were submitted, 199 were removed from the analysis since the respondents had failed to fill out the gender, age, start watching the lectures, complete watching the lectures, or instructional design items. This left 1602 valid respondents, of which 828 were female (52\%) and 774 were male (48\%). The oldest subject was 63-years-old while the youngest was 15-years-old, with an average respondent age of 23.5 and a standard deviation of 3.2. This distribution of age and gender is illustrative of the general demographic composition of students taking online classes in South Korea (Suh \& Kim, 2013). The respondents took a wide variety of classes in the OCU. These classes filled a wide range of subjects 
with the largest amount being liberal arts courses (33\%), following with social sciences courses (17\%) in second place, third, information technology courses (15\%), then lifestyle and health courses (12\%), fifth, management and business classes (8\%), then foreign language classes (7\%), seventh, natural science classes, and finally, classes related to design (2\%). This breakdown of course areas reflect the distribution that is generally found within the OCU (Kobayashi \& Kim, 2010).

\section{Research Procedures and Data Collection}

The beginning of the study was a series of short qualitative interviews with 10 students who had taken OCU classes in the second semester of 2015. The questions that formed a part of these interviews focused on the nature of learner-to-learner activities, the types of instruction that the students encountered, and how they felt instructional materials in the OCU affected their learning experience. When asked to describe their general opinion of the learning environment in the OCU, a typical response was that of Kim, "I just watched the videos and did the exams, there was other things but I didn't do them." When asked about the contents of the video lectures, Lee said, "the videos were good ... I thought they were interesting sometimes the professor appeared sometimes we saw some graphs or videos or something." This view could be contrasted with Park who said, "It was just the professor standing and talking... it was boring to me." These contrasting views along with a lack of differing types of instruction outside of the video lectures led to the researchers to view the instructorcentered aspect of most OCU lessons as being important and requiring of investigation. Following the interviews, a broad set of survey items was given to 92 students. This survey contained items ranging from cheating online to learner-to-learner interaction, to automated feedback systems. From this survey, several issues relating to media variety and lecture diversity, as well as student learning showed to be relevant to students. Because of this, a more specific survey designed to be taken by a larger sample of students was developed and used for this study. A broad survey of OCU members' perceptions was felt to be the best method of understanding the most important aspect of OCU instruction, which is the video lecture.

The survey was initially written in English, and then translated into Korean. The Korean translation was checked by an expert in the OCU and online learning. The translations were found to be accurate and a fair representation of the English items. This translated survey was put into a Google Sheets form and a link to the survey was sent to the OCU's main administrative offices. After the survey was checked for its appropriateness by the OCU's administration, the survey link was posted on the main information board of the OCU, with a message inviting the students to participate in the research. The link was active from April 2oth, 2016 until it was taken offline on May 20th, 2016.

\section{Instrument Development}

To generate the indicators for measuring audio, visual, and total diversity, two methods were used. First, 20 videos from the OCU were watched and aspects of the lectures were noted by the authors. Furthermore, 10 students who were part of the initial interview part of this research were asked to describe what happened in the lectures both visually and auditorily. The list created by the authors was then discussed with them, and the students agreed that the list seemed to accurately note the differing aspects of the lectures that they had observed.

To understand audio and visual lecture diversity, students were asked to respond to two separate 
items. The first item related to audio diversity and asked students to: Check all of the auditory aspects that the lecture contained. Below this, the students could check boxes with the options: The professor speaking, sound effects, music in the background, someone other than the professor speaking, the professor speaking while music is playing, when the professor spoke, words were emphasized. The responses were then coded into six separate variables as either occurring or not occurring, and they were combined by addition into a single additive index: audio diversity. The second item the students could respond to regarding lecture diversity asked students to: Check all of the visual aspects that the lecture contained. Below this, the students could check boxes with the options: Embedded scrolling text, a video of something (not the professor), animation, pictures, graphs and or tables, slides, professor writing on the whiteboard/blackboard, Khan Style. The responses were then coded into seven separate variables as either occurring or not-occurring and then combined by addition into a single additive index: visual diversity. Finally, to create the main construct used in this research, total diversity, the audio diversity and visual diversity constructs were combined into a final additive index.

Four items were used to generate the germane load measurement used in this study. The items were from Leppink et al.'s (2013) The development of an instrument for measuring cognitive load, which contains an overview of the measurement of the three types of cognitive load: intrinsic, extraneous and germane. The present study uses items from this research in the form of the four items: The lecture really enhanced my understanding of the topic, the lecture really enhanced my knowledge and understanding of the of the class subject, the lecture really enhanced my understanding of the concepts associated with the class subject, the lecture really enhanced my understanding of concepts and definitions. These items are slightly modified from Leppink et al.'s (2013) research in that this research replaces the word "activity" with the word "lecture" to focus in on the most salient aspect of the OCU's instruction. Cronbach's Alpha for the germane load construct was .962, which is appropriate for research of this type.

\section{Results}

To get an overview of the main variables used in this study, descriptive statistics for the combined total diversity, total visual, and total audio were calculated (see Table 1). All the diversity variables had a minimum value of 0 and a maximum value of 10 , with a mean of 3.3 for total diversity, 3.2 for visual diversity, and 3.4 for audio diversity. The germane load construct is also shown in Table 1 , and had a much higher average that the combined diversity constructs with a mean of 6.3, which gives some evidence that the students feel like they are learning in the OCU.

Table 1

Combined Constructs Descriptive Statistics

\begin{tabular}{|l|l|l|l|l|l|}
\hline & N & Minimum & Maximum & Mean & Std. Deviation \\
\hline Total Diversity & 1602 & 0 & 10 & 3.2872 & 1.79704 \\
\hline Total Visual & 1602 & 0 & 10 & 3.2358 & 2.11805 \\
\hline
\end{tabular}




\begin{tabular}{|l|l|l|l|l|l|}
\hline Total Audio & 1602 & 0 & 10 & 3.3558 & 2.01284 \\
\hline Germane load & 1602 & 0 & 10 & 6.2946 & 2.27613 \\
\hline
\end{tabular}

To understand the main research questions, Pearson's bivariate correlations were used. As can be seen in Table 2, there is a positive statistically significant relationship between germane load and total diversity (.263), visual diversity (.224), and audio diversity (.231). All of these relationships had $p$ values of <.01. Also shown on Table 2 is the relationship between audio, visual, and total diversity. This is unsurprising considering their relationship as a combined variable in total diversity. Also, there is a relationship between age and gender (.318). This is likely because Korean males are forced to serve two years in the military, which they often take before they start university study, or after their freshman year is completed.

Table 2

Correlations between Diversity Constructs and Germane Load $(N=1602)$

\begin{tabular}{|l|l|l|l|l|l|l|l|}
\hline & & 1 & 2 & 3 & 4 & 5 & 6 \\
\hline 1 & Gender & 1 & & & & & \\
\hline 2 & Age & $.318^{* *}$ & 1 & & & & \\
\hline 3 & Total diversity & 0.041 & 0.011 & 1 & & & \\
\hline 4 & Audio combined & .049 & 0.02 & $.809^{* *}$ & 1 & & \\
\hline 5 & Visual combined & 0.011 & 0.001 & $.908^{* *}$ & $.489^{* *}$ & 1 &. \\
\hline 6 & Germane load & -0.018 & 0.025 & $.263^{* *}$ & $.224^{* *}$ & $.231^{* *}$ & 1 \\
\hline
\end{tabular}

${ }^{*}$ Correlation is significant at the .o1 level.

The indicators used to generate the diversity constructs were calculated and can be seen in Table 3. In terms of audio, the most common indicator was the professor speaking, then sound effects, then words being emphasized, then music, then another (not the professor) speaking, and finally music over the professor, which was the least checked indicator. In terms of visual indicators, the most checked indicator was rolling text, then pictures, then slides, then graphs and/or tables, then someone (not the professor), then Khan style, then the professor in front of a whiteboard, and finally animation, which had the lowest incidence among the visual diversity items. Furthermore, each indicator was correlated with germane load. All audio indicators had a statistically significant positive relationship with germane load, except for the professor speaking, which was neutral. As with audio indicators, all visual indicators were positively correlated with germane load excluding one, rolling text, which was neutral. It is of note that the two indicators that were neutral in regards to germane load were in the cases of both audio and visual indicators, the most common indicators. 
Table 3

Indicators and Their Correlations with Germane Load and Occurrence of the Indicators

\begin{tabular}{|l|l|l|l|l|}
\hline Indicators & $\begin{array}{l}\text { Germane } \\
\text { load }\end{array}$ & $\begin{array}{l}\text { Containing } \\
\text { the } \\
\text { indicator }\end{array}$ & $\begin{array}{l}\text { Not } \\
\text { containing } \\
\text { the } \\
\text { indicator }\end{array}$ & $\begin{array}{l}\text { Total } \\
\text { responses }\end{array}$ \\
\hline Audio Sound effects & $.113^{* *}$ & 601 & 1001 & 1602 \\
\hline $\begin{array}{l}\text { Audio someone other than } \\
\text { professor }\end{array}$ & $.120^{* *}$ & 230 & 1372 & 1602 \\
\hline Audio music & $.136^{* *}$ & 399 & 1203 & 1602 \\
\hline Audio the professor speaking & 0.039 & 1542 & 60 & 1602 \\
\hline Audio music over prof speaking & $.092^{* *}$ & 148 & 1454 & 1602 \\
\hline Audio words were emphasized & $.182^{* *}$ & 538 & 1064 & 1602 \\
\hline Visual rolling text & 0.025 & 949 & 653 & 1602 \\
\hline $\begin{array}{l}\text { Visual professor writing on a } \\
\text { white board }\end{array}$ & $.100^{* *}$ & 364 & 1238 & 1602 \\
\hline Visual Khan style & $.102^{* *}$ & 410 & 1192 & 1602 \\
\hline Visual slides & $.082^{* *}$ & 723 & 879 & 1602 \\
\hline Visual animation & $.127^{* *}$ & 243 & 1359 & 1602 \\
\hline Visual pics & $.165^{* *}$ & 884 & 718 & 1602 \\
\hline Visual graphs & $.114^{* *}$ & 601 & 1001 & 1602 \\
\hline Visual not the professor & $.172^{* *}$ & 439 & 1163 & 1602 \\
\hline & & & & \\
\hline
\end{tabular}

\section{Discussion}

This study showed that there is a positive relationship between the variety of multimedia used in lectures and germane load. To find out if total lecture diversity had a positive relationship with germane load, all of the indicators measuring differing types of delivery were combined to examine the relationship. Total diversity, which refers to all of the auditory and visual multimedia indicators combined, had a statistically significant relationship with germane load. Multimedia addressing each processing channel (auditory and visual) was examined by looking at the relationship between the combined indicators of each channel and germane load. The combined auditory multimedia showed a statistically significant positive correlation with germane load, and the combined visual indicators also had a statistically positive relationship with germane load. 
To get a more detailed picture of the relationships, each individual indicator was examined in regards to its correlation with germane load. Every individual indicator showed a positive relationship with two exceptions, the professor speaking (audio) and rolling text (visual). This was interesting because those two indicators were the most commonly checked indicators. The fact that both the professor speaking and rolling text appear to be so common within an e-lecture may indicate that they represent the standard delivery of e-learning, and do not necessarily contribute to diverse delivery. They were neutral in regards to their relationship with germane load while all other indicators that represent diversity showed a positive relationship with germane load. This adds support to the notion that diverse multimedia delivery helps increase levels of germane load.

The results of this study do not align with aspects of some research on diversity and learning (Chandler \& Sweller, 1991; Kizilcec et al., 2015; Mayer, 2014; Mayer and Moreno, 2003; Rasch \& Schnotz, 2009; Schnotz \& Rasch, 2005; Sweller, 1999; Sweller et al., 1998). However, unlike the present study, some past research examines the relationship between multimedia and learning under specific conditions during specific points during an e-learning lecture. But the current study involves a broader conceptualization of multimedia diversity across multiple lectures and topics. Although there may be isolated incidents where diverse delivery of audio, visual or a combination of both audio and visual media may be harmful to germane load, the current study shows that in a general sense, diversity of lecture delivery has a positive effect.

The relationships found between diversity of multimedia and germane load are supported by past research that not only provide theoretical support for, but also show evidence that both auditory and visual media increase student understanding of the content (Alwitt et al., 1980; Atkinson et al., 2005; Calvert \& Gersh, 1987; Calvert \& Scott, 1989; Day et al., 2006; Kim et al., 2011; Luzón \& Letón, 2015; Mann, 1979; Mautone \& Mayer, 2001; Moreno \& Mayer, 1999; Salomon, 1994; Sweller \& Chandler, 1994; van Gog et al., 2005; Wagley, 1978; Zhang, Zhou, Briggs, \& Nunamaker, 2006). These papers support the notion that students learn better with multiple representations of content, enabling them to effectively integrate new information with previous knowledge, further increasing germane load (Baggett, 1984; Paivio, 1991; Schmidt-Weigand \& Scheiter, 2011; Solomon, 1994; Verdi \& Kulhavy, 2002). Looking at total audio and total video separately reveals that the correlation between visual and germane load was slightly higher than the correlation between audio and germane load. This is supported by the bushiness hypothesis, which states that knowledge obtained from visual presentations are more accessible in the memory than knowledge obtained from verbal presentations due to the learner's ability to make better associations between visuals and content (Baggett, 1984).

The current study also showed that sound effects, music, music over the professor speaking, someone other than professor speaking, and words emphasized are all positively correlated with germane load. Although some research claims sound effects, music, and background music are forms of extraneous audio that is detrimental in specific situations, this study showed that it can be beneficial when looked at over the course of a lecture. These findings are supported by the arousal theory, which suggests that stimulating sounds are actually helpful for cognitive processing (Weiner, 1990; Renninger, Hidi, \& Krapp, 1992). Additionally, the correlation between words emphasized and germane load gives credibility to the signaling effect, which involves emphasizing specific words used to describe the content so students can gain a better understanding (Mautone \& Mayer, 2001). Examining individual visual indicators also provides some valuable insight into what is going on between media delivery and 
germane load. This study showed that visuals other than the professor, slides, animation, pictures, and graphs all positively correlated with germane load. Animation and pictures specifically, have been shown by past research to enhance student understanding of the content by providing a facilitating effect, which helps students make connections between the visuals and the content (Salomon, 1994; Sweller \& Chandler, 1994; van Gog et al., 2005). In regards to visual text, although no relationship was found between rolling text and germane load, the professor writing on a white board and Khan style both had a positive relationship with germane load. Both of these visual represent the writing of text, with Khan style representing it in animated written from. Research supports the use of written text, specifically animated written text, to aid the learning process by helping students retain information and recall it at a later time in the lecture for longer periods of time after it was delivered (Luzón \& Letón, 2015).

\section{Conclusion}

Because lecture delivery is a major aspect of MOOCs, it is important to find effective ways of delivering content through various forms of media. Content should be delivered in a way that helps students' comprehension, which further adds to the learning experience. The findings of the present study are important in that they show that the use of total diversity, auditory diversity, as well as visual diversity have a positive relationship with germane load. Germane load, not only directly contributes to learning, but represents how well the students understand the content of the lecture. These findings could serve as a practical guideline for e-learning instructors who wish to enhance student learning with MOOCs. That guideline would be that increasing the variety of media including auditory, visual, and total diversity will have a positive benefit on students' learning experience. This study shows that combining various forms of both auditory and visual media may help students cognitively make connections between the media and the content, further supporting learning within e-learning courses.

Although positive relationships were found that are practical for developing effective e-learning courses, there are limitations to this study. This study used survey data, with students checking the types of visual and auditory indicators they perceived. Specific experimental conditions could be used to clearly differentiate the variety of levels of diversity. The results of this type of experiment would help clarify and strengthen research into this area. This would provide further insight into what is actually going on between multimedia delivery and germane load. The results of this study; however, serve as a starting point for better understanding relationships between multimedia and germane load. Overall, the fact that positive relationships were found between various forms of multimedia delivery of content and germane load serve as a useful first step to promoting a better understanding of elearning lectures.

\section{References}

About OCU. (n.d.). Open Cyber University [website]. Retrieved from http://www.ocu.ac.kr/foreign/english/About_ocu/subo5.asp 
Alraimi, K. M., Zo, H., \& Ciganek, A. P. (2015). Understanding the MOOCs continuance: The role of openness and reputation. Computers \& Education, 8o, 28-38.

Alwitt, L. F, Anderson, D. R., Lorch, E. P., \& Levin, S. R. (1980). Preschool children's visual attention to attributes of television. Human Communication Research, 7, 52-67.

Atkinson, R. K., Mayer, R. E., \& Merrill, M. M. (2005). Fostering social agency in multimedia learning: Examining the impact of an animated agent's voice. Contemporary Educational Psychology, 30, 117-139. http://dx.doi.org/10.1016/j.cedpsych.2004.07.001

Austin, K. A. (2009). Multimedia learning: Cognitive individual differences and display design techniques predict transfer learning with multimedia learning modules. Computers and Education, 53(4), 1339-1354. http://doi.org/10.1016/j.compedu.2009.06.017

Breslow, L., Pritchard, D. E., DeBoer, J., Stump, G. S., Ho, A. D., \& Seaton, D. T. (2013). Studying learning in the worldwide classroom: Research into edX's first MOOC. Research \& Practice in Assessment, 8 (March 2012), 13-25. Retrieved from http://www.rpajournal.com/dev/wpcontent/uploads/2013/05/SF2.pdf

Baggett, P. (1984). Role of temporal overlap of visual and auditory material in forming dual media associations. Journal of Educational Psychology, 76, 408-417.

Chandler, P., \& Sweller J. (1991). Cognitive load theory and the format of instruction. Cognition and Instruction, 8 (4), 293-332.

Calvert, S. L., \& Gersh, T. L. (1987). The selective use of sound effects and visual inserts for children's comprehension of television content. Journal of Applied Developmental Psychology, 8, 363375 .

Calvert, S. L., \& Scott, M. C. (1989). Sound effects for children's temporal integration of fast-paced television content. Journal of Broadcasting and Electronic Media, 33, 233-246.

Cierniak, G., Scheiter, K., \& Gerjets, P. (2009). Explaining the split-attention effect: is the reduction of extraneous cognitive load accompanied by an increase in germane cognitive load? Computers in Human Behavior, 25, 315-324.

Clark, J. M., \& Paivio, A. (1991). Dual coding theory and education. Educational Psychology Review, $3(3), 149-210$.

Day, J. A., Foley, J. D., \& Catrambone, R. (2006). Investigating multimedia learning with web lectures. GVU Technical Report GIT-GVU-06-25. GA: Georgia Institute of Technology. Retrieved from http://smartech.gatech.edu/handle/1853/13141

De Jong, T. (2010). Cognitive load theory, educational research, and instructional design: some food for thought. Instructional Science, 38(2), 105-134.

Goldstone, R. L., \& Son, J. Y. (2005). The transfer of scientific principles using concrete and idealized 
simulations. The Journal of the Learning Sciences, 14, 69-110.

Han, S. (2012). A study on the development of a course evaluation tool for Cyber University Consortium in Korea. In T. Kim, S. Mohammed, C. Ramos, J. Abawajy, B. Kang, \& D. Slezak (Eds.), Computer applications for web, human computer interaction, signal and image processing, and pattern recognition. Springer Berlin Heidelberg (pp. 331-337). Conference proceedings http://link.springer.com/chapter/10.1007/978-3-642-35270-6_46

Jung, I., \& Rha, I. (2001). A virtual university trial project: Its impact on higher education in South Korea. Innovations in Education and Teaching International, 38(1), 31-41.

Kaplan, A. M., \& Haenlein, M. (2016). Higher education and the digital revolution: About MOOCs, SPOCs, social media, and the Cookie Monster. Business Horizons, 59(4), 441-450.

Kalyuga, S., Chandler, P., \& Sweller, J. (1999). Managing split-attention and redundancy in multimedia instruction. Applied Cognitive Psychology, 13, 351-371.

Kim, J., Kwon, Y., \& Cho, D. (2011). Investigating factors that influence social presence and learning outcomes in distance higher education. Computers \& Education, 57(2), 1512-1520. http://doi.org/10.1016/j.compedu.2011.02.005

Kobayashi, T., \& Kim, Y. S. (2010). The status of cyber education in Korean higher education: A potential for East Asian linkage in higher education. 6th Joint Conference on Education Technology Proceedings, Naturo, 2-19. Received from http://id.nii.ac.jp/1146/00003502/

Kolfschoten, G., Lukosch, S., Verbraeck, A., Valentin, E., \& Vreede, G.J.D. (2010). Cognitive learning efficiency through the use of design patterns in teaching. Computers \& Education, 54(3), $652-660$.

Kizilcec, R. F., Bailenson, J. N., \& Gomez, C. J. (2015). The instructor's face in video instruction: Evidence from two large-scale field studies. Journal of Educational Psychology, 107(3), 724.

Lee, H. \& Lee, S. (2015). Analysis of various influences and factors on academic persistence of cyber university students. International Journal of Service, Science and Technology, 8(10), pp 211222.

Leppink, J., Paas, F., Van der Vleuten, C. P., Van Gog, T., \& Van Merriënboer, J. J. (2013). Development of an instrument for measuring different types of cognitive load. Behavior Research Methods, 45(4), 1058-1072.

Leppisaari, I., Herrington, J., Vainio, L., \& Im, Y. (2013). Authentic e-learning in a multicultural context: virtual benchmarking cases from five countries. Journal of Interactive Learning Research, 24(1), 53-73.

Lim, K., Kang, M., \& Park, S. Y. (2016). Structural relationships of environments, individuals, and learning outcomes in Korean online university settings. The International Review of 
Research in Open and Distributed Learning, 17(4).

Lowe, R. K. (1999). Extracting information from an animation during complex visual learning. European Journal of Psychology of Education, 14, 225- 244.

Luzón, J. M., \& Letón, E. (2015). Use of animated text to improve the learning of basic mathematics. Computers \& Education, 88, 119-128.

Mann, R. (1979). The effect of music and sound effects on the listening comprehension of fourth grade students (Unpublished doctoral dissertation), North Texas State University, Denton.

Mautone, P. D., \& Mayer, R. E. (2001). Signaling as a cognitive guide in multimedia learning. Journal of Educational Psychology, 81, 240-246.

Mayer, R. E. (1997). Multimedia learning: Are we asking the right questions? Educational Psychologist, 32(1), 1- 19.

Mayer, R. E. (2014). Cognitive theory of multimedia learning. The Cambridge handbook of multimedia learning, 43-71.

Mayer, R. E., \& Anderson, R. B. (1991). Animations need narrations: An experimental test of a dualcoding hypothesis. Journal of Educational Psychology, 83(4), 484-490.

Mayer, R. E., \& Anderson, R. B. (1992). The instructive animation: Helping students build connections between words and pictures in multimedia learning. Journal of educational Psychology, 84(4), 444-452.

Mayer, R. E., \& Moreno, R. (2003). Nine ways to reduce cognitive load in multimedia learning. Educational Psychologist, 38(1), 43-52.

Moore, M. G., \& Kearsley, G. (2011). Distance education: A systems view of online learning. Belmont, CA: Cengage Learning.

Moreno, R., \& Mayer, R. E. (1999). Cognitive principles of multimedia learning: The role of modality and contiguity. Journal of Educational Psychology, 91(2), 358-368.

Mousavi, S. Y., Low, R., \& Sweller, J. (1995). Reducing cognitive load by mixing auditory and visual presentation modes. Journal of Educational Psychology, 87(2), 319-334.

National Center for Education Statistics. (2008). Distance education at degree-granting postsecondary institutions: 2006-07. US Department of Education. NCES 2009-044.

Owston, R., Lupshenyuk, D., \& Wideman, H. (2011). Lecture capture in large undergraduate classes: Student perceptions and academic performance. Internet and Higher Education, 14(4), 262268. http://doi.org/10.1016/j.iheduc.2011.05.006

Paivio, A. (1991). Dual coding theory: Retrospect and current status. Canadian Journal of Psychology, 
45(3). $255-287$.

Rasch, T., \& Schnotz, W. (2009). Interactive and non-interactive pictures in multimedia learning environments: Effects on learning outcomes and learning efficiency. Learning and Instruction, 19(5), 411-422.

Renninger, K., Hidi, S. E., \& Krapp, A. E. (1992). The role of interest in learning and development. Hillsdale, NJ: Erlbaum. Salomon, G. (1994). Interaction of media, cognition, and learning. Hillsdale, NJ: Erlbaum.

Schmeck, A., Opfermann, M., van Gog, T., Paas, F., \& Leutner, D. (2015). Measuring cognitive load with subjective rating scales during problem solving: differences between immediate and delayed ratings. Instructional Science, 43(1), 93-114.

Schmidt-Weigand, F., \& Scheiter, K. (2011). The role of spatial descriptions in learning from multimedia. Computers in Human Behavior, 27(1), 22-28.

Schnotz, W., \& Rasch, T. (2005). Enabling, facilitating, and inhibiting effects of animations in multimedia learning: Why reduction of cognitive load can have negative results on learning. Educational Technology Research and Development, 53(3), 47-58.

Shadiev, R., Hwang, W. Y., Huang, Y. M., \& Liu, T. Y. (2015). The impact of supported and annotated mobile learning on achievement and cognitive load. Journal of Educational Technology \& Society, 18(4), 53-69.

Sims, V. K., \& Hegarty, M. (1997). Mental animation in the visuospatial sketchpad: Evidence from dual-task studies. Memory \& Cognition, 25, 321- 332.

Suh, S., \& Kim, S. (2013). Study on policy for an entrance quota of cyber universities. Seoul, Korea: Korea Educational Information and Research Service.

Sun, P. C., \& Cheng, H. K. (2007). The design of instructional multimedia in e-Learning: A media richness theory-based approach. Computers \& Education, 49(3), 662-676.

Sweller, J. (1999). Instructional Design in Technical Areas. Camberwell, Australia: ACER Press.

Sweller, J. (2005). Implications of cognitive load theory for multimedia learning. In R. E. Mayer (Ed.), The Cambridge Handbook of Multimedia Learning (pp. 19-30). New York: Cambridge University Press.

Sweller, J., \& Chandler, P. (1994). Why some material is difficult to learn. Cognition and Instruction, $12,185-233$.

Sweller, J., Van Merriënboer, J. J. G., \& Paas, F. (1998). Cognitive architecture and instructional design. Educational Psychology Review, 10, 251-296.

van Gog, T., Ericsson, K. A., Rikers, R. M. J. P., Paas, F., Gog, T., Ericsson, K. A., \& Paas, F. (2005). 
Instructional design for advanced learners: Establishing connections between the theoretical frameworks of cognitive load and deliberate practice. Educational Technology Research and Development, 53(3), 73-81. http://doi.org/10.1007/BFo2504799.

van Merriënboer, J. J. G. (1997). Training complex cognitive skills. Englewood Cliffs, NJ: Educational Technology Publications.

Verdi, M. P., \& Kulhavy, R. W. (2002). Learning with maps and texts: An overview. Educational Psychology Review, 14, 27-46.

Wagley, M. (1978). The effect of music on affective and cognitive development of sound-symbol recognition among preschool children (Unpublished doctoral dissertation), Texas Woman's University, Denton.

Weiner, B. (1990). History of motivational research in education. Journal of Educational Psychology, $82,616-622$.

Wong, A., Leahy, W., Marcus, N., \& Sweller, J. (2012). Cognitive load theory, the transient information effect and e-learning. Learning and Instruction, 22(6), 449-457.

Yuan, L., \& Powell, S. (2013). MOOCs and open education: Implications for higher education [White Paper]. Retrieved from http://publications.cetis.ac.uk/2013/667

Zhang, J. (1997). The nature of external representations in problem solving. Cognitive Science, 21, 179-217.

Zhang, D., Zhao, J. L., Zhou, L., \& Nunamaker, J. F. (2004). Can e-learning replace classroom learning? Communications of the ACM, 47(5), 75-79. http://doi.org/10.1145/986213.986216.

Zhang, D., Zhou, L., Briggs, R. O., \& Nunamaker, J. F. (2006). Instructional video in e-learning: Assessing the impact of interactive video on learning effectiveness. Information \& Management, 43(1), 15-27.

Athabasca

University

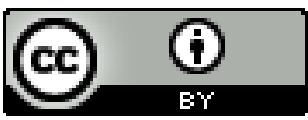

